\title{
Evaluation of Neutrophil-to-Lymphocyte and Platelet-to-Lymphocyte Ratios as Reliable Biomarkers for the Diagnosis of Perforated Acute Appendicitis: A Retrospective case control study
}

Hui Zhou ( $\nabla$ onedreame@aliyun.com )

Wuhan Third Hosiptal https://orcid.org/0000-0002-3757-0352

Jinling Xu

Department of Endocrinology and Metabolism, The General Hospital of Central Theater Command JianTao Han

Department of General Surgery, The Third Hospital of Wuhan

\section{Xingwang Xie}

Department of General Surgery, The Third Hospital of Wuhan

HanBing Xu

Department of General Surgery, The Third Hospital of Wuhan

\section{Research}

Keywords: Perforated acute appendicitis, neutrophil to lymphocyte ratio, platelet to lymphocyte ratio

Posted Date: June 8th, 2020

DOI: https://doi.org/10.21203/rs.3.rs-32681/v1

License: (c) (1) This work is licensed under a Creative Commons Attribution 4.0 International License.

Read Full License 


\section{Abstract \\ Background}

To investigate the relationship among neutrophil to lymphocyte ratio (NLR),platelet to lymphocyte ratio (PLR) of patients with perforated acute appendicitis and its clinical significancel

\section{Methods}

The present study selected 243 patients who underwent appendectomy presented with acute appendicitis from January 2013 and December 2015ロAll patients were confirmed by pathology $\square A A$ patients were divided into Perforated acute appendicitis(PAA)group and Non-perforated acute appendicitis $\square$ NPAA $\square$ group $\square$ The routine blood test results were collected pre-operation and calculated the NLR and PLR $\square T 0$ analyze the relationship among the NLR,PLR, Age, Gender, WBC count, Operation approach in PAA group and NPAA group.

\section{Results}

The NLR and PLR of PAA group were significantly higher than that of the NPAA group $(\mathrm{P}<0.0001$ and $\mathrm{P}=$ 0.039);Cut-off value NLR ( $\geq 8.96)$ and PLR $(\geq 173.03)$ of were PAA group were significantly higher than that of the NPAA group $(P<0.0001$ and $P=0.012)$. Multiple logistic regression analysis identified NLR as independent variables.

\section{Conclusions}

We suggest that the preoperative NLR and PLR are useful parameters to differentiate among PAA and NPAA.

\section{Background}

Acute appendicitis (AA) is almost a daily occurrence in the general surgery department. Despite being just so common, but the mechanism of AA remains poorly understood in the past few decades. It still requires early diagnosis and prompt management to avoid complications such as perforation, subsequent peritonitis and appendiceal abscess nowadays ${ }^{1}$. In the development of inflammation of the appendix vermiformis, the direct luminal obstruction is the major pathophysiological mechanism. And recent theories associated with appendicitis focus on genetic factors, environmental influences and infection.

The diagnosis of acute appendicitis is clinical symptoms, scoring systems and imaging methods. There are few methods for evaluating the severity of appendicitis itself before surgery. In many surgical centers, it is attempt to delay appendectomy for 12-24 hours due to decrease the operative risk during the night. 
And it not seems to increase complications ${ }^{2}$. Biomarker reflect the severity of acute appendicitis may be correlated with data for inflammatory markers such as white blood cell count (WBC), neutrophil count, platelet count and C-reactive protein (CRP) ${ }^{3,4}$. Neutrophils regulate mast cells, epithelial cells and macrophages, and play an important role in inflammatory events. NLR is a marker of inflammation in various diseases and Changes in the NLR can be an early sign of bacterial and viral infections. Another parameter that has been used for the diagnosis of infection is the PLR. Platelets are cells that help in modulating various inflammatory conditions; therefore, changes in PLR may be a useful indicator of acute infection, including AA. NLR, PLR, in particular, is regarded as an inflammatory marker not only in acute inflammatory diseases, but also in several chronic inflammatory diseases ${ }^{5}$, including cancer ${ }^{6}$. The aims of this study were to determine the value of NLR and PLR in diagnosing AA and predicting its severity.

\section{Materials And Methods}

This retrospective study included 243 patients (150 men, 93 women), for whom sufficient data were valuable. They had undergone appendectomy for $A A$, operated by the same trained surgical team at the Department of General Surgery, Wuhan Third Hospital, between January 2013 and December 2015. All patients involved in this study gave their informed consent. The institutional review board and Ethics Committee of The Third Hospital of Wuhan approved this study. All patients have given their informed consent. To divide the patients into two groups depended upon whether perforated or not, we calculated the cutoff values of Demographic characteristics such as Age, WBC count, NLR, PLR using receive operating characteristic curve (ROC) analyses. Exclusion criteria included the following: hematological disorders; chronic liver or kidney disease; chronic obstructive pulmonary disease; asthma; any viral, bacterial or parasitic infection; cancer or autoimmune disease. Patients with incomplete records were also excluded.

\section{Statistical analysis}

Data are presented as mean $\pm S D$. Differences between the groups were analyzed using the $x^{2}$ test or Student's $t$ test. Odds ratios (OR) with $95 \%$ confidence interval $(\mathrm{Cl})$ were calculated on the basis of multivariate analysis, performed using logistic regression. Recommended cut-off values of NLR, PLR, WBC were determined using ROC analysis. Statistical analyses were performed using the SPSS 22.0 (SPSS Inc, Chicago, Illinois) at a significance level of $P<0.05$.

\section{Result}

A total of 263 patients were enrolled in the study, after the exclusion of 20 patients owing to multiple missing values or non-operation. The data of 243 patients were retained (Table 1). There were 203 patients in Non-perforated group and 40 patients in perforated group. There were significant differences between Non-perforated group and perforated group in mean ages (38.67 \pm 15.93 and $48.98 \pm 19.61)$ (P囚0.001), Operation approach (open appendectomy (OA) /laparoscopic appendectomy $(L A))(P=0.033)$, 
$\operatorname{NLR}(10.44 \pm 8.39$ and $16.08 \pm 10.48)(P \unrhd 0.001), P L R(194.32 \pm 113.96$ and $237.51 \pm 149.98)(P=0.039)$. There was no significant difference in Gender, WBC count.

Table 1

Comparison of clinical presentation and laboratory findings

\begin{tabular}{|c|c|c|c|c|}
\hline Variable & & NAPP group $(n=203)$ & PAA group $(n=40)$ & $P *$ \\
\hline Ages (years) & Mean \pm SD & $38.67 \pm 15.93$ & $48.98 \pm 19.61$ & $\nabla 0.001$ \\
\hline \multirow[t]{2}{*}{ Gender } & Male & 125 & 25 & \multirow[t]{2}{*}{0.913} \\
\hline & Female & 78 & 15 & \\
\hline WBC count $\left(\times 10^{9} / \mathrm{L}\right)$ & Mean \pm SD & $12.15 \pm 4.3$ & $13.58 \pm 4.45$ & 0.057 \\
\hline \multirow[t]{2}{*}{ Operation } & OA & 32 & 12 & \multirow[t]{2}{*}{0.033} \\
\hline & LA & 171 & 28 & \\
\hline NLR & Mean \pm SD & $10.44 \pm 8.39$ & $16.08 \pm 10.48$ & $\otimes 0.001$ \\
\hline PLR & Mean \pm SD & $194.32 \pm 113.96$ & $237.51 \pm 149.98$ & 0.039 \\
\hline
\end{tabular}

Cut-off values calculated using ROC analysis is depicted in Fig. 1. For the diagnosis of PAA, ages $\geq 50.5$ had $62.5 \%$ sensitivity and $73.9 \%$ specificity, WBC count $\geq 12.6(x 109 / L)$ had $62.5 \%$ sensitivity and $55.2 \%$ specificity, NLR $\geq 8.96$ had $77.5 \%$ sensitivity and $58.6 \%$ specificity and PLR $\geq 173.03$ had $70 \%$ sensitivity and $51.7 \%$ specificity (Table 2). There were significant differences between Non-perforated group and perforated group in ages $(\geq 50.5$ and $₫ 50.5)(P \llbracket 0.001)$, WBC count $(\geq 12.6$ and $\otimes 12.6)(P=0.041)$, Operation approach (open appendectomy (OA) /laparoscopic appendectomy (LA) ) $(P=0.033), N L R(\geq$

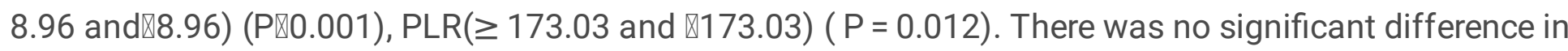
Gender (Table 3).

Table 2

Receiver operating characteristic analysis of Demographic characteristics with NPAA/PAA group

\begin{tabular}{|llll|}
\hline Variable & AUC & SE $^{a}$ & $95 \%$ Cl $^{\mathbf{b}}$ \\
\hline Age (years) & 0.653 & 0.0525 & $0.590-0.713$ \\
\hline NLR & 0.535 & 0.0476 & $0.470-0.599$ \\
\hline PLR & 0.537 & 0.0499 & $0.472-0.601$ \\
\hline WBC count & 0.588 & 0.0489 & $0.523-0.650$ \\
\hline
\end{tabular}


Table 3

Demographic characteristics and hematologic markers between NPAA and PAA group

\begin{tabular}{|c|c|c|c|c|}
\hline Variable & & NPAA group $(n=203)$ & PAA group $(n=40)$ & $P *$ \\
\hline \multirow[t]{2}{*}{ Ages (years) } & $\geq 50.5$ & 41 & 25 & $\otimes 0.001$ \\
\hline & $\nabla 50.5$ & 162 & 15 & \\
\hline \multirow[t]{2}{*}{ Gender } & Male & 125 & 25 & 0.913 \\
\hline & Female & 78 & 15 & \\
\hline \multirow[t]{2}{*}{ WBC count $\left(\times 10^{9} / \mathrm{L}\right)$} & $\geq 12.6$ & 91 & 25 & 0.041 \\
\hline & $\bigotimes 12.6$ & 112 & 15 & \\
\hline \multirow[t]{2}{*}{ Operation } & OA & 32 & 12 & 0.033 \\
\hline & LA & 171 & 28 & \\
\hline \multirow[t]{2}{*}{ NLR } & $\geq 8.96$ & 84 & 31 & $\bowtie 0.001$ \\
\hline & $\bigotimes 8.96$ & 119 & 9 & \\
\hline \multirow[t]{2}{*}{ PLR } & $\geq 173.03$ & 98 & 28 & 0.012 \\
\hline & $\otimes 173.03$ & 105 & 12 & \\
\hline
\end{tabular}

The results of the multiple logistic regression analysis are presented in Table 4. The Age, NLR was significant independent predictors of a diagnosis of PAA.

Table 4

multivariate logistic regression analysis of Demographic characteristics with NPAA/PAA group

\begin{tabular}{|llll|}
\hline Variable & Odds ratio & $95 \% \mathrm{Cl}$ & $P^{*}$ \\
\hline Age $(\geq 50.5 / \varangle 50.5$ years $)$ & 6.427 & $3.010-13.725$ & $\otimes 0.001$ \\
\hline NLR $(\geq 8.96 / \varangle 8.96)$ & 4.742 & $2.058-10.925$ & $\otimes 0.001$ \\
\hline
\end{tabular}

\section{Discussion}

AA is part of the most common surgical emergencies ${ }^{7}$. Diagnosis of AA largely depends on a clinical diagnosis supported by laboratory and imaging studies. AA is a well-known entity with remarkable signs and symptoms, but there is not a single parameter to diagnose it easily. Complicated appendicitis occurs once the appendix has become gangrenous and/or has perforated with numerous degrees of peritonitis. The rate of complicated appendicitis is slowly increasing and has been reported at an incidence of 12$30 \% 8,9$. A recent study suggests that perforation is not necessarily the inevitable result of appendiceal 
obstruction. PAA may occur more commonly in patients with altered inflammatory responses or alterations in the colonic microbiome ${ }^{10}$. In the elderly people, the morbidity rate and mortality rate are higher in the presence of PAA ${ }^{11,12}$. In our study, the mean age of PAA group obviously older than NPAA group. Appendectomy is the gold standard for the management of AA since the late 1800s. And subsequent technological advances and improvement in the 1990s, the LA has gradually become a mainstay of treatment for AA. Some studies indicate that LA provides advantages in terms of shorter length of stay, less postoperative pain and faster recovery time, but there is a controversy with the application of $L A$ in $P A A^{12}$. A range of novel biomarkers has been suggested during the past decade, including WBC and CRP, some studies have shown that increase in CRP and WBC are associated with the severity of $A A$, but these do not have external validity. In this study, we also found that NLR, PLR are reliable predictors of PAA, and NLR is significant independent predictors of diagnosis of PAA.

NLR is a novel inflammatory marker and the determination of NLR is a simple test can be easily ascertained using blood parameters involved in the complete blood count. Goodman ${ }^{13}$ first suggested that the use of NLR in the diagnosis of AA. Then a number of studies showed that NLR played a useful role in the diagnosis of AA and was different between non-complicated AA and complicated AA. Markar $\mathrm{SR}^{14}$ has demonstrated that NLR is greater diagnostic accuracy than either WBC or CRP alone in AA and is an independent predictor of positive appendicitis histology. Takayuki Shimizu ${ }^{15}$ demonstrated that a higher NLR is closely associated with severe appendicitis. In a retrospective study by Kahramanca 16 reported that an NLR cutoff value of 5.74 was found to be critical for complicated Acute Appendicitis. Furthermore, Ishizuka ${ }^{17}$ demonstrated that NLR above 8 was significant for gangrenous appendicitis. Khan $\mathrm{A}^{18}$ confirmed that an NLR $>6.36$ or $\mathrm{CRP}>28$ were statistically associated with complicated acute appendicitis, and NLR had a better area under the ROC curve compared to CRP for predicting severe appendicitis. Similarly, in our study, the higher NLR was observed in the perforated appendectomy group $(16.08 \pm 10.48)$ and a cutoff value of 8.96 was found to be critical for PAA. Multiple logistic regression analysis determined that the examination of NLR is a significant screening test for the diagnosis of PAA. This conclusion supports the consequence of our present study that NLR is significant independent predictors of diagnosis of PAA.

PLR is a combination of the PLT and lymphocyte counts. The research of PLR is focused on cancers and inflammation. In a recent study, NLR, and PLR were evaluated in patients treated for familial Mediterranean fever ${ }^{19}$; PLR was deemed increased in patients with the condition compared with the control group. In another study by Nazik ${ }^{20}$, use of NLR, PLR, IMA, and ESR values may be helpful in the diagnosis of appendicitis. In our study, PLR was increased with inflammation and was higher in the perforated appendectomy group $(237.51 \pm 149.98)$. However, multiple logistic regression analysis determined that the examination of PLR is not an independent factor for the diagnosis of PAA.

Our study has several limitations. Firstly, this retrospective study was carried out without estimating adequate sample size, so it is difficult to fully ascertain if there are unknown confounding variables that affect NLR and PLR validity. And only patients who underwent appendectomy were included. Secondly, 
symptom onset to blood test time interval was not included in this study. Lastly, other clinical data such as symptoms and physical examinations were not investigated in this study. This is a study showing promising role of NLR, PLR at PAA.

\section{Conclusion}

From the above discussion, the conclusion can be reached that NLR, PLR are a good predictor of PAA. And NLR is significant independent predictors of a diagnosis of PAA.

\section{Abbreviations}

NLR

neutrophil to lymphocyte ratio; PLR:platelet to lymphocyte ratio; AA:Acute appendicitis; PAA:Perforated acute appendicitis; NPAA:Non-perforated acute appendicitis; WBC:white blood cell count; CRP:C-reactive protein; ROC:receive operating characteristic curve; OR:Odds ratios; Cl:confidence interval; OA:open appendectomy; LA:Iaparoscopic appendectomy.

\section{Declarations}

\section{Ethics approval and consent to participate}

The consent was obtained from the patients for publication of this paper. The ethics committee of the Wuhan Third Hospital has approved this study.

\section{Consent for publication}

Written informed consent was obtained from the patients for publication.

\section{Availability of data and materials}

The datasets used and/or analyzed during the current study are available from the corresponding author on reasonable request.

\section{Competing interests}

The authors declare that they have no competing interest.

\section{Funding}

Not applicable.

\section{Author's Contributions}


$\mathrm{HZ}$ and JLX contributed to the conception of the study. $\mathrm{HZ}$ contributed significantly to analysis and manuscript preparation; $\mathrm{HZ}$ performed the data analyses and wrote the manuscript; JTH, XWX and HBX helped perform the analysis with constructive discussions.

\section{Acknowledgements}

We are grateful to the patients for giving consent for the paper. We thank MuXi Zhou for the help of literature search.

\section{References}

1. Bhangu A, Soreide K, Di Saverio S, Assarsson JH, Drake FT. Acute appendicitis: modern understanding of pathogenesis, diagnosis, and management. Lancet (London England) Sep. 2015;26(10000):1278-87. 386(.

2. Abou-Nukta F, Bakhos $\mathrm{C}$, Arroyo $\mathrm{K}$, et al. Effects of delaying appendectomy for acute appendicitis for 12 to 24 hours. Archives of surgery (Chicago III: 1960) May. 2006;141(5):504-6. discussioin 506507.

3. Farooqui W, Pommergaard HC, Burcharth J, Eriksen JR. The diagnostic value of a panel of serological markers in acute appendicitis. Scandinavian journal of surgery: SJS : official organ for the Finnish Surgical Society the Scandinavian Surgical Society Jun. 2015;104(2):72-8.

4. Yazar FM, Urfalioglu A, Bakacak M, Boran OF, Bulbuloglu E. Efficacy of the Evaluation of Inflammatory Markers for the Reduction of Negative Appendectomy Rates. The Indian journal of surgery Feb. 2018;80(1):61-7.

5. Feng JR, Qiu X, Wang F, et al. Diagnostic Value of Neutrophil-to-Lymphocyte Ratio and Platelet-toLymphocyte Ratio in Crohn's Disease. 2017;2017:3526460.

6. Liang Y, Wang W, Li J, et al. Combined Use of the Neutrophil-Lymphocyte and Platelet-Lymphocyte Ratios as a Prognostic Predictor in Patients with Operable Soft Tissue Sarcoma. Journal of Cancer. 2018;9(12):2132-9.

7. Sandell E, Berg M, Sandblom G, et al. Surgical decision-making in acute appendicitis. BMC surgery Jun. 2015;2:15:69.

8. Livingston EH, Woodward WA, Sarosi GA, Haley RW. Disconnect between incidence of nonperforated and perforated appendicitis: implications for pathophysiology and management. Annals of surgery Jun. 2007;245(6):886-92.

9. Oliak D, Yamini D, Udani VM, et al. Can perforated appendicitis Be diagnosed preoperatively based on admission factors? Journal of gastrointestinal surgery: official journal of the Society for Surgery of the Alimentary Tract Sep-Oct. 2000;4(5):470-4.

10. Flum DR. Clinical practice. Acute appendicitis-appendectomy or the "antibiotics first" strategy. The New England journal of medicine May. 2015;14(20):1937-43. 372. 
11. Malindi TJ, le Grange SMO. Outcome of appendicitis in the elderly in University and Pelonomi hospital. South African journal of surgery Suid-Afrikaanse tydskrif vir chirurgie Jun. 2017;55(2):56.

12. Renteria O, Shahid Z, Huerta S. Outcomes of appendectomy in elderly veteran patients. Surgery. Jun 162018.

13. Goodman DA, Goodman CB, Monk JS. Use of the neutrophil:lymphocyte ratio in the diagnosis of appendicitis. The American surgeon Mar. 1995;61(3):257-9.

14. Markar SR, Karthikesalingam A, Falzon A, Kan Y. The diagnostic value of neutrophil: lymphocyte ratio in adults with suspected acute appendicitis. Acta chirurgica Belgica Sep-Oct. 2010;110(5):543-7.

15. Shimizu T, Ishizuka M, Kubota K. A lower neutrophil to lymphocyte ratio is closely associated with catarrhal appendicitis versus severe appendicitis. Surgery today Jan. 2016;46(1):84-9.

16. Kahramanca S, Ozgehan G, Seker D, et al. Neutrophil-to-lymphocyte ratio as a predictor of acute appendicitis. Ulusal travma ve acil cerrahi dergisi = Turkish journal of trauma emergency surgery: TJTES Jan. 2014;20(1):19-22.

17. Ishizuka M, Shimizu T, Kubota K. Neutrophil-to-lymphocyte ratio has a close association with gangrenous appendicitis in patients undergoing appendectomy. International surgery Oct-Dec. 2012;97(4):299-304.

18. Khan A, Riaz M, Kelly ME, et al. Prospective validation of neutrophil-to-lymphocyte ratio as a diagnostic and management adjunct in acute appendicitis. Irish journal of medical science May. 2018;187(2):379-84.

19. Kucuk A, Erol MF, Senel S, et al. The role of neutrophil lymphocyte ratio to leverage the differential diagnosis of familial Mediterranean fever attack and acute appendicitis. The Korean journal of internal medicine Mar. 2016;31(2):386-91.

20. Nazik S, Avci V, Kusku Kiraz Z. Ischemia-modified albumin and other inflammatory markers in the diagnosis of appendicitis in children. Ulusal travma ve acil cerrahi dergisi = Turkish journal of trauma emergency surgery: TJTES Jul. 2017;23(4):317-21.0.

\section{Figures}




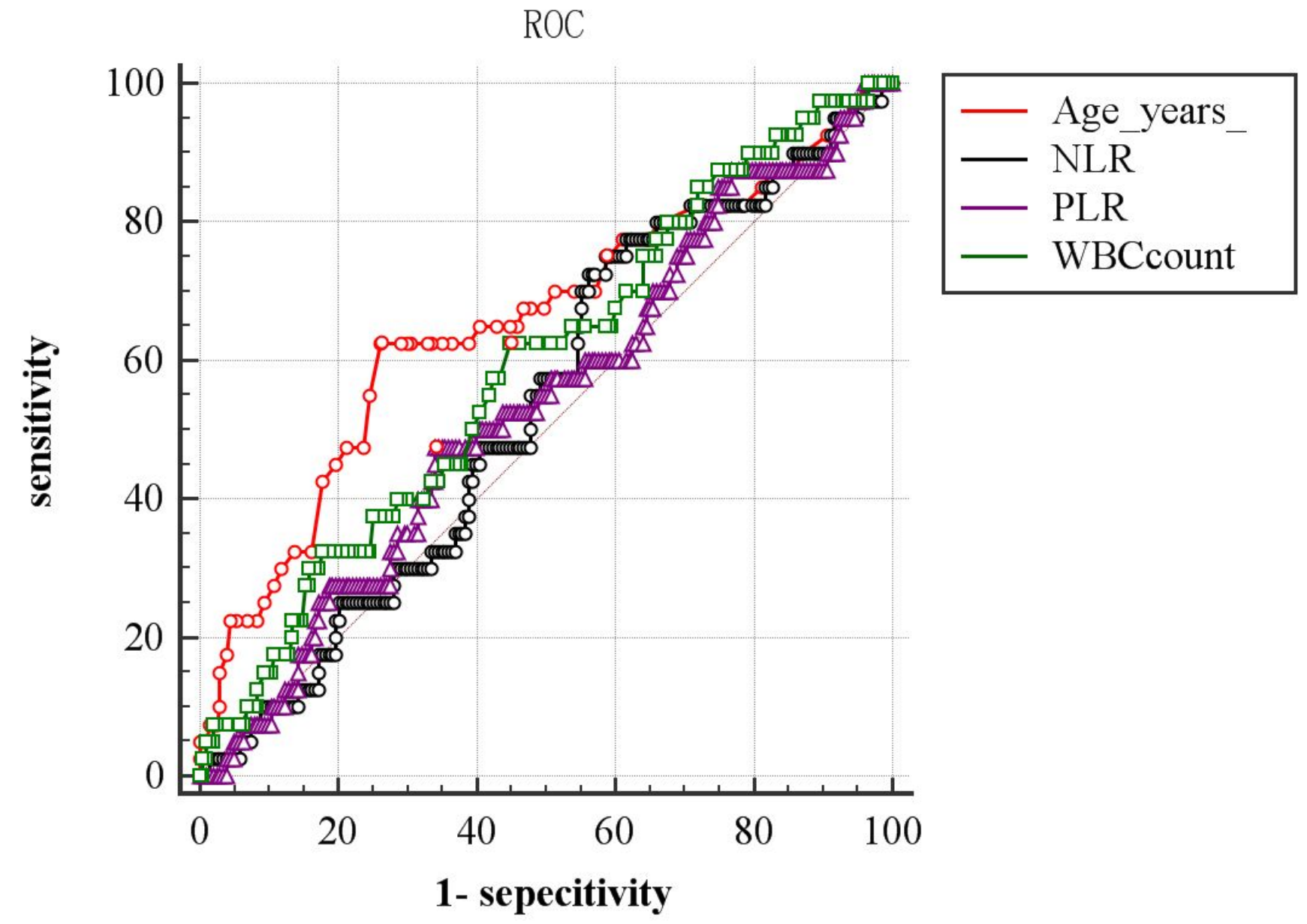

Figure 1

Comparison of the receiver operating characteristics curve for diagnosing Perforated Acute Appendicitis for the Age, NLR, PLR and the WBC count.

\section{Supplementary Files}

This is a list of supplementary files associated with this preprint. Click to download.

- supplement9.doc 